\title{
A Model for Increasing Electronic Payment Tendency (EPT) using Gamification
}

\author{
Roshan LAVASTI \\ \# Master of IT, Organizational Architecture Discipline, \\ Islamic Azad University, Urmia Branch, Urmia, Iran. \\ ${ }^{1}$ roshanlavasti@hotmail.com
}

\begin{abstract}
Nowadays, e-banking enables customers to conduct their financial activities in a virtual environment using Web and Internet technology. The purpose of the study was to identify the factors affecting EPT. The factors affecting examination of EPT by Saman Bank customers in this study were divided into six factors: performance expectancy (PE), effort expectancy (EE), social influence (SI), personal priorities (PPs), facilitating conditions (FC), and personal norm (PN). The population was the customers of Saman Bank, West Azerbaijan branches, using the service temporarily and continuously. The study was applied in terms of purpose and descriptive-analytical in terms of nature and method. Data collection method was through a questionnaire. Structural equation modeling (SEM) and LISREL software were used to test the hypotheses. In the model examined, the fitness indices showed the appropriateness of the conceptual model and the results of data analysis were as follows: there is a linear relationship between PE, EE, SI, FC, PPs, PPs, and PN with behavioral intention (BI) and EPT, and a linear relationship between the intention of EPT, which is an intermediary variable, and EPT.
\end{abstract}

Keyword - Gamification, E-banking, Intention to use, Technology Acceptance

\section{Introduction}

Over time and the emergence of various banking practices, the banking industry gradually expanded [5]. The developments that the banking industry faces in the recent two decades have ended in major changes in the form of money and resource transfer systems and introduced concepts like electronic money and electronic transfer of resources. These two concepts create a new kind of banking called e-banking. E-banking can be defined as using advanced technologies of networks and telecommunications for the transfer of resources (money) in the banking system [18].

For the development of e-banking, there is a serious need for culture-building to attract and economically justify the exploitation of these systems for customers [6] 2008. Electronic businesses use the information to provide targeted products and services related to their customers. The goal of gamification in electronic payment services is to engage the customer in his normal banking and financial activities more. This feature affects the multiplicity and extent of using digital banking products and services, reducing the costly branch-centered banking.

Gamification is not always building a game. It can also be about changing behaviors, attracting people, creating habits, and solving problems in a game-based manner. Using mobiles or web pages accessible to the public everywhere, using gamification techniques and mobile-based banking services, people are encouraged to use this type of service and benefit from them and can learn both new banking services and save their time and energy.

Gamification is the same as using computer game concepts for the daily applications of software, applications and websites [1]. Gamification clearly affects customer motivation and forces them to interact and use the banking services, which ultimately leads to increased profitability and value added through customers for the bank [11]. With the theme of the interactive model of organizational gamification in Business to Customer (B2C) using Technology Acceptance Model (TAM), [23] have shown a positive effect of gamification on the supply chain of the organization and encouraging customers to use the services.

Gamification refers to the use of game elements, techniques, and methods of game design and the purpose of training games in non-game environments to encourage individuals to use and solve or learn complex problems. As gamification follows the goal of education, it improves the training process. Gamification has many goals in a variety of topics like health, business, medical education, education at different levels of learning, used to take advantage of the adoption of gamification in business and mobile banking.

On the other hand, given the rapid increase in the provision and improvement of Internet banking services by global banking groups, it seems that it is time for users to review the adoption of Internet banking. The study has not been done extensively and completely in the electronic and banking industry, and the aspects of gamification and gamification frameworks have not been explored in their use in electronic and banking payments. 


\section{Theoretical Foundations}

\section{E-banking}

E-banking is a set of processes performed by customers to conduct banking activities without the need for physical branches of banks [5]. E-banking is the provision of banking services through a publicly accessible network (Internet or Extranet) with high security. Table (1) is used to look at the two modes of traditional and ebanking.

Table 1

\begin{tabular}{|l|l|}
\hline \multicolumn{2}{|c|}{ Comparison of traditional and e-banking [9] } \\
\hline \multicolumn{1}{|c|}{ E-banking } & \multicolumn{1}{c|}{ Traditional banking } \\
\hline - Electronic transfer order & - Paper transfer order \\
- Cyberspace & - Physical space \\
- Providing diverse and broader services & - Providing limited services \\
- No time limit (24-hour and 7-day access) & - Limited office hours \\
- Reducing human errors & - High human errors \\
- Electronic information processing & - Need for a lot of force to process information \\
- Making money by fees & - Making money through profit margin \\
- Multifunctional Banks (equipped with electronic & - Relying on bank branches \\
facilities) & - Contamination in the physical delivery of cash \\
- Converting cash to electronic money (Decrease & \multicolumn{2}{|c|}{} \\
in pollution) &
\end{tabular}

The automation of the banking system or the development of e-banking is a complex and targeted process in three levels and work stage, where the customer can have the proper service. These three levels are as follows:

The first level, which needs an intellectual change in the structure of banks, is formed by fundamental changes in managers' insights for creating a fundamental transformation in business processes and optimizing the planning and execution of affairs in the bodies of banks [10].

At the second level, which is called the information exchange network, intra-branch, between the branches of one bank, and inter-branch communication systems are selected. Facilities such as telecommunication, satellite, fiber optic, wireless networks, and other systems are among the topics to be addressed to reach a common standard [10].

The third level, which is the hacking automation service, uses five different ways of implementing service practices. Web-based Internet, ATMs, sales terminals, physical branches and fixed and mobile phones have been investigated and exploited in recent years as platforms for service delivery [10].

In a study entitled "Examining the factors in accepting e-banking," [6] (2007) showed that features like relative advantage, ease, testability, compatibility, and risk have an effective role in EPT, but demographic variables like income, age, education status and marital status do not have much effect on EPT.

\section{Infrastructures and the contexts needed for the development of e-banking}

\section{Public access to infrastructure for electronic communications}

The most important feature and point in selecting this tool is the need to consider the first principle of e-banking, customer-orientation in using e-banking systems. This tool includes using an appropriate Internet bandwidth network, internal networks such as intranets, satellite systems, fiber optic lines, mobile phones, landlines and so on.

\section{Development of financial and banking infrastructure}

One of the most important measures taken by the banks in becoming an e-bank is creating infrastructures like credit cards, smart cards, hardware development of banking networks, and the expansion of ATMs. It also has the right connection to adapt the banks' internal networks and sales terminals to expand the role of smart cards offered by the bank in daily transactions.

\section{Developing legal infrastructure in e-banking}

Any new technology requires legal acceptance for being accepted and developed prior to public acceptance. It should be noted that the general public does not accept the high risk in economic matters, especially if there is a new window for movement and economic activity, in which case it will not play a role in the development of this process until assuring legal backing [2].

\section{Technology Acceptance Model (TAM)}

According to TAM, the behavior of using an information technology is determined by the intention to use that particular system, and the intention to use it is determined by the usefulness of the technology in question from the user's perspective and the ease of use of the system by him [3]. 


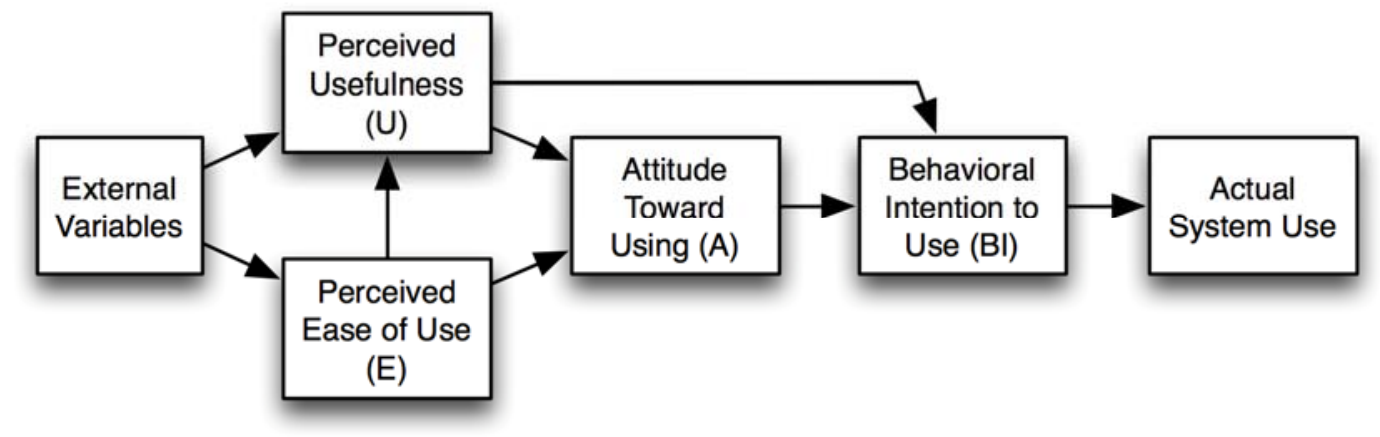

Figure 1 components and relationships of the modified technology acceptance model [19], [20],[21]

TAM helps senior executives and develops online banking products and information system developers to predict user behavioral intention. This knowledge, or at least an additional insight, allows them to develop methods that make it easier for users of the system to enable banking and technology professionals to come up with new ways to meet the needs and expectations of online banking customers [17].

\section{Internet banking acceptance}

In the late 1990s, everyone used to focus on the Internet banking and its acceptance. Revising the published papers on this topic over the past 10 years, internet-banking literature is included in two descriptive and relational categories [12].

Descriptive studies focus on identifying the characteristics of internet banking adopters, their responses, attitudes, acceptance barriers, or features that make Internet banking more attractive to future adopters. The goal of relational studies is exclusively to explore the influential variables on the adoption of Internet banking and, in general, the use of one of the adoption models of new technologies [12].

Internet banking as a technological innovation in banking has not been completely examined, although there are studies on the adoption of information technology in banking. Internet banking publication is defined as a process passed through Internet banking through a given channel over time to members of a social system. There are four main components in this definition: 1) Internet banking, 2) communication channels, 3) time, and 4) people in a social system. As acceptance of a particular technology depends on several factors, Internet banking acceptance is a complex issue [12].

[22] studied "The acceptance of Internet banking in Taiwan." They examined the effect of the added construct of perceived trustworthiness (perceived security and privacy) on the intention to use Internet banking according to the technology acceptance model. The results confirmed the significant effects of perceived usefulness, perceived ease of use and perceived trustworthiness on the intention to use.

In another study entitled "The pattern of internet banking acceptance by customers," [13] concluded that a perception of the usefulness and perception of security had the greatest effect on the acceptance of Internet banking by customers. In a study entitled "Accepting e-banking among customers of Shiraz banks," [15] showed that the ease of use, usefulness and customer trust have been effective in acceptance of e-banking, but the level of education of customers has a direct effect on the acceptance of e-banking." In a study entitled "Examining the effect of factors affecting the acceptance and use of e-banking (Case Study of Melli Bank Branches of Arak)," [2] (2012) concluded that trusting the traditional structure of banks and accepting and using their e-banking are not significantly related to customers, and the most important reason for the lack of acceptance and use of e-banking by customers is the habit of using traditional services.

\section{Gamification}

Games may adapt to varying degrees of users in terms of attitude, knowledge, cognitive and physical perception, health or pleasure [14]. These are the main features of fun games that provide customers with an experience of interaction, even when used for product promotion and trading, where entertainment and sales are connected in an integrated way with software program [8].

While games are often played for fun, serious games and gamification use game design for other purposes, except for entertainment in a non-game context (the serious game is on learning and gamification about motivation) [4]. Gamification is the use of computer game concepts for the daily applications of software, applications and websites [1].

Gamification values to the needs and desires of humans, and responds to them, such as the need for simplicity, fun, social engagement, rewards and competition. Thus, using all of these features, the customers are emotionally engaged and mentally involved, and thus adapt to different banking solutions. Gamification clearly 
affects customer motivation and forces them to interact and use banking services, which ultimately ends in increased profitability and value added through customers for the bank [11]. The model of [19] was used in this study. The research model of the researcher has major variables called PE, EE, SI, and FC.

There are significant definitions of gamification by [4], [24], and [25]. [4] define gamification as "the use of game elements in non-game contexts" [7].

[26] examined the effect of gamification on the acceptance of e-payment services and mobile banking using the integrated approach of technology acceptance and use, resulting in a strong direct relationship between gamification and the intention to use mobile banking services [16] examined the effect of gamification on online learning systems and the positive effect of gamification on foreign language learning. According to the mentioned points, the conceptual model is presented.

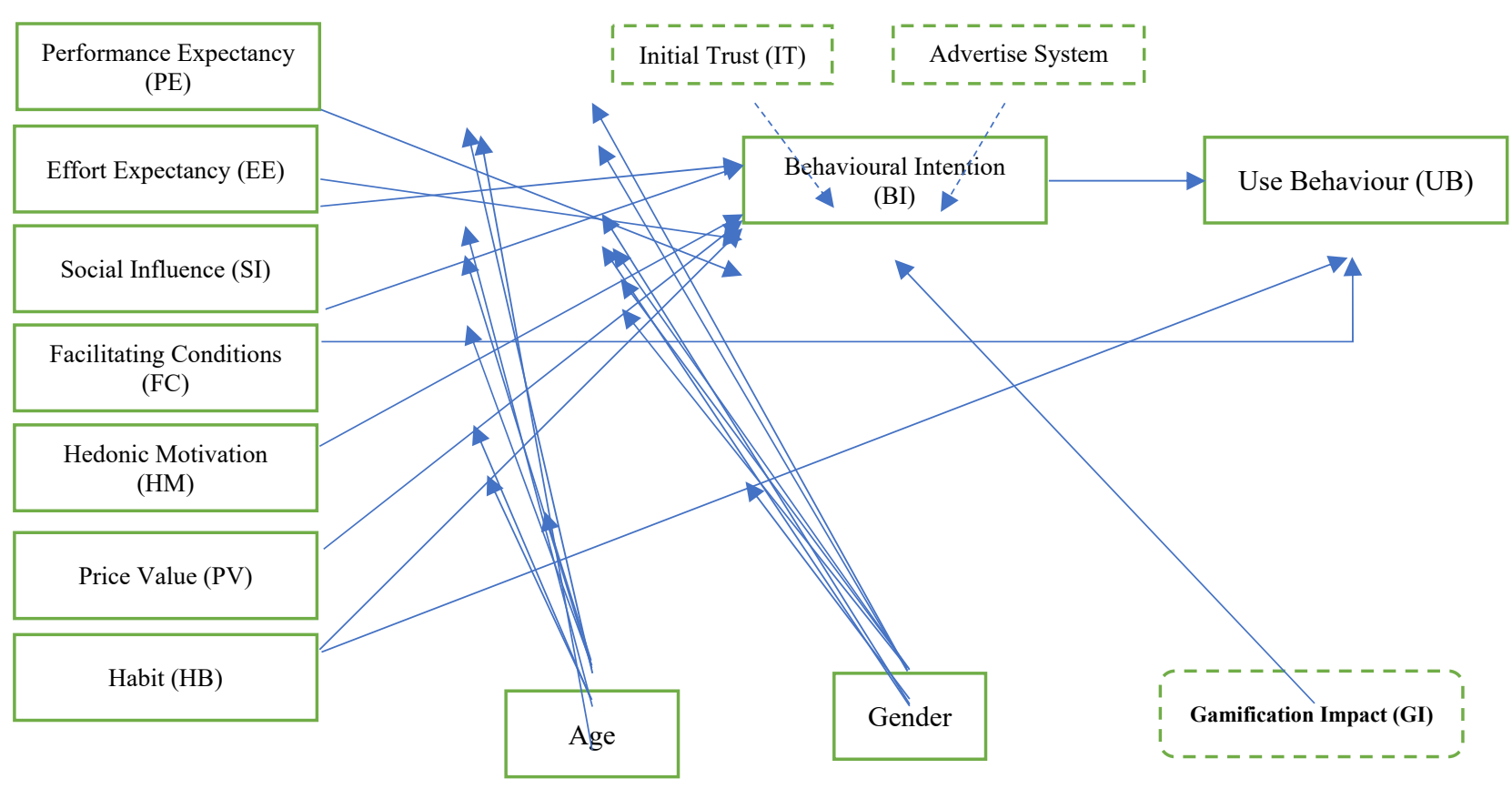

Figure 2. Conceptual model of the study

\section{Methodology}

The study was applied in terms of purpose and descriptive non-experimental in terms of data collection. In terms of method and implementation, the study was descriptive-analytical with an emphasis on the correlation. Finally, in terms of data collection, the study was of field type. The population was Saman Bank customers and Saman Kish Electronic Payment Company, which uses the Banking Mission and Banking and Banking software 724 of the company. As the population forms a large population, we obtain the population volume using the following formula:

$$
n=\frac{z_{a}^{2} / 2 s_{\frac{2}{x}}^{2}}{\varepsilon^{2}}=\frac{(1.96)^{2} *(0.490)^{2}}{(0.05)^{2}}=370 \quad \text { Equation } 1
$$

Table 2

\begin{tabular}{|c|c|c|c|c|c|}
\hline & \multicolumn{4}{|c|}{ Separation of the completed questionnaires by cities } \\
\hline \multirow{3}{*}{ Sample size } & Centre & \multicolumn{2}{|c|}{ East } & \multicolumn{2}{c|}{ South } \\
\cline { 2 - 6 } & Urmia & Khoy & Salmas & Naghadeh & Mahabad \\
\cline { 2 - 6 } & 150 & 70 & 50 & 60 & 40 \\
\hline
\end{tabular}

A questionnaire consisting of 33 items was used to collect data adopted from the questionnaire designed by Venkatesh (2003). After the initial design, the research questionnaire was revised to increase the validity using the opinions of the professors and the necessary changes were made. The reliability of the questions, asked to measure each variable using Cronbach's alpha coefficient, is as follows: 
Table 3

\begin{tabular}{|c|c|c|}
\hline \multicolumn{3}{|c|}{ Variables Cronbach's Alpha } \\
\hline Row & Variable & Cronbach's alpha value \\
\hline 1 & PE & $90.8 \%$ \\
\hline 2 & EE & $82 \%$ \\
\hline 3 & SI & $76.9 \%$ \\
\hline 4 & E-banking & $77.2 \%$ \\
\hline 5 & FC & $85.3 \%$ \\
\hline 6 & PPs & $83.7 \%$ \\
\hline 7 & Subjective norm & $81.3 \%$ \\
\hline 8 & EPT & $76.6 \%$ \\
\hline
\end{tabular}

SEM was used to analyze the data and test the hypotheses. Data collected from the questionnaire were analyzed in SPSS and LISREL.

\section{Results}

Table (4) describes the variables, the standard deviation, and their variance.

Table 4

\begin{tabular}{|c|c|c|c|c|c|c|c|c|}
\hline & \multicolumn{7}{|c|}{ Description of the variables } \\
\hline Variable & Frequency & Min. & Max. & Mean & SD & Variance & Skewness & Kurtosis \\
\hline PE & 370 & 1 & 5 & 3.8883 & 0.67393 & 0.454 & -0.773 & 1.005 \\
\hline EE & 370 & 1.8 & 5 & 4.0395 & 0.56222 & 0.316 & -0.404 & -0.057 \\
\hline SI & 370 & 1.5 & 5 & & 3.3881 & 0.67741 & 0.459 & -0.124 \\
\hline $\begin{array}{c}\text { E-banking } \\
\text { acceptance }\end{array}$ & 370 & 1 & 5 & 3.5174 & 0.64264 & 0.413 & -0.274 & 0.037 \\
\hline FC & 370 & 1.75 & 5 & 3.3773 & 0.61323 & 0.376 & 0.065 & -0.235 \\
\hline PPs & 370 & 2.5 & 5 & 3.9277 & 0.48932 & 0.293 & -0.15 & -0.195 \\
\hline Subjective norms & 370 & 2 & 5 & 3.7865 & 0.5429 & 0.295 & -0.145 & -0.157 \\
\hline EPT & 370 & 1.75 & 5 & 3.7181 & 0.60417 & 0.365 & -0.288 & 0.03 \\
\hline
\end{tabular}




\section{Examining the research measurement model}

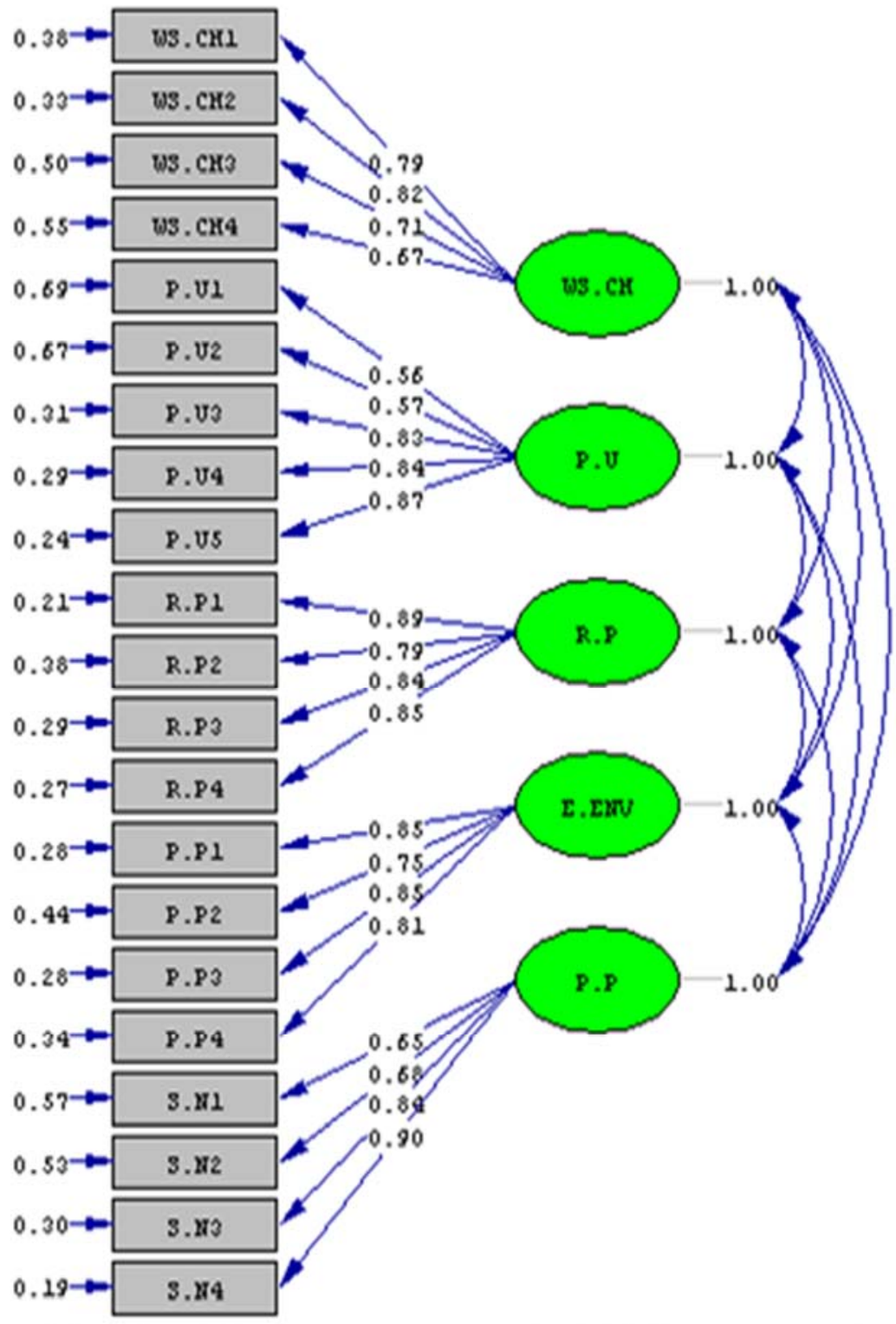

\section{Chi-Square $=532.56, d f=179, \quad P-v a l u e=0.00000$, RMSEA $=0.068$}

Figure 3 Exogenous variables model in standard numbers mode.

Figure (3) shows the relevance of each question of the questionnaire to the variable in question. The fit indices in terms of fitness indicate that the model is approached appropriately, because the ratio of Chi square to degree of freedom is less than 3, which is at a significant level of 0.00000 and RMSEA is below 0.08 , which can be stated that this model has an acceptable fit with reality. 


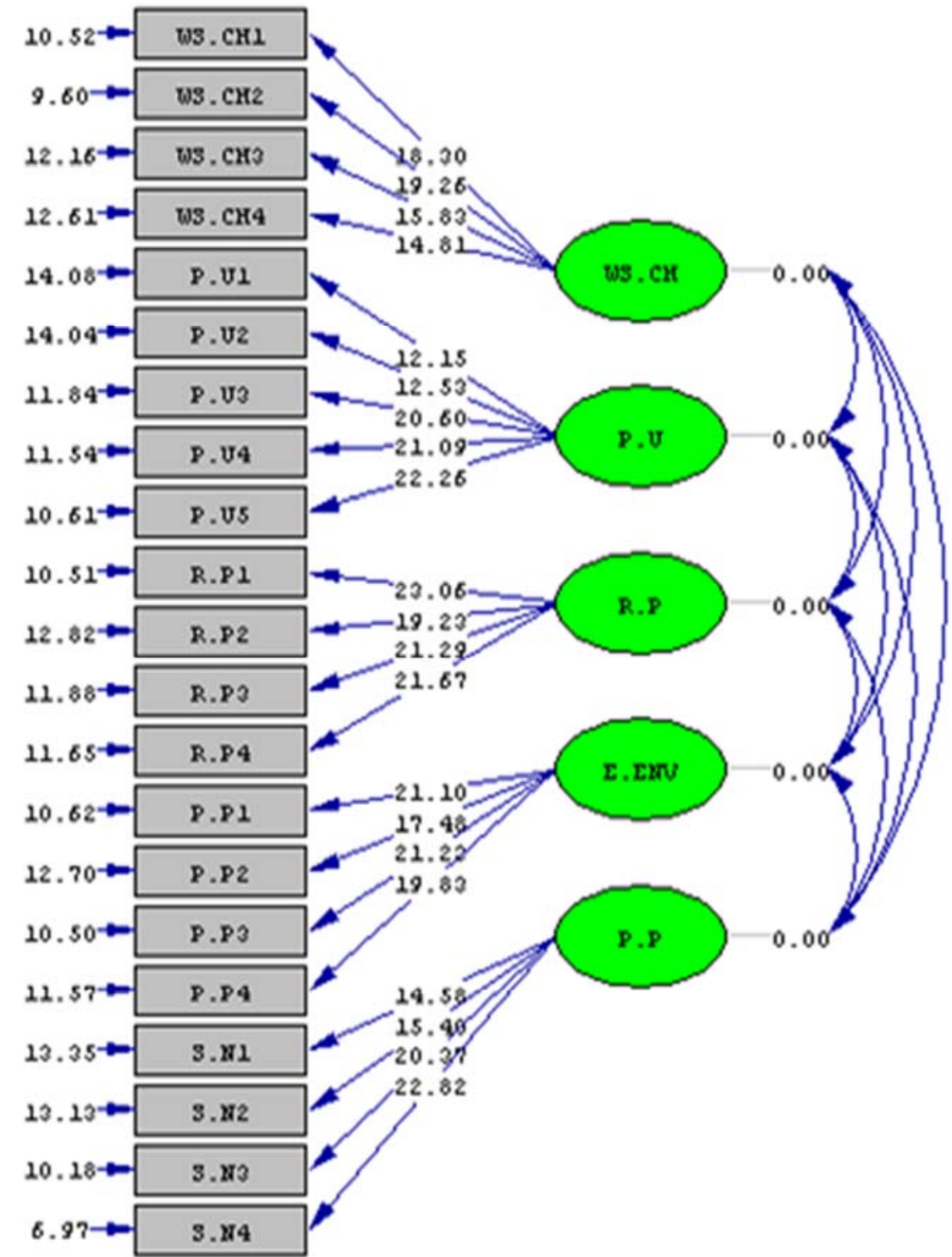

Chi-Square $=532.56, d f=179, \mathrm{p}-\mathrm{value}=0.00000$, RMSEA $=0.068$

Figure 4 Model of exogenous variables in significant numbers mode.

The following table shows a variety of fitness and significance indices for the exogenous variable measurement model.

Table 5

\begin{tabular}{|c|c|c|c|c|c|c|c|}
\hline \multicolumn{6}{|c|}{ Fitness indices of the research model for the exogenous variable measurement model } \\
\hline Index & RMSEA & $\frac{x^{2}}{d_{f}}$ & GFI & IFI & CFI & NFI & NNFI \\
\hline Value & 0.068 & 2.97 & 0.89 & 0.95 & 0.95 & 0.92 & 0.94 \\
\hline Desired mode & $0 \leq \& \leq 0.1$ & $1 \leq \& \leq 5$ & $0.8 \leq \& \leq 1$ & $0.8 \leq \& \leq 1$ & $0.8 \leq \& \leq 1$ & $0.8 \leq \& \leq 1$ & $0.8 \leq \& \leq 1$ \\
\hline
\end{tabular}


Figure 4 shows the relevance of each question of the questionnaire to the desired variable. The fit indices in terms of fitness show that the model is approached appropriately, as Chi square ratio to the degree of freedom is less than 3, RMSEA is below 0.08, and IFI and CFI indices are above 0.90, and only NFI, GFI, and NNFI indices are above $80 \%$ showing that the model is above the average.

According to the model of exogenous variables and index tables, it is seen that all $t$ values in significant numbers states are greater than 1.96 showing that all the correctness of the questions designed for exogenous variables is confirmed. In simpler terms, the model for measuring exogenous variables is confirmed.

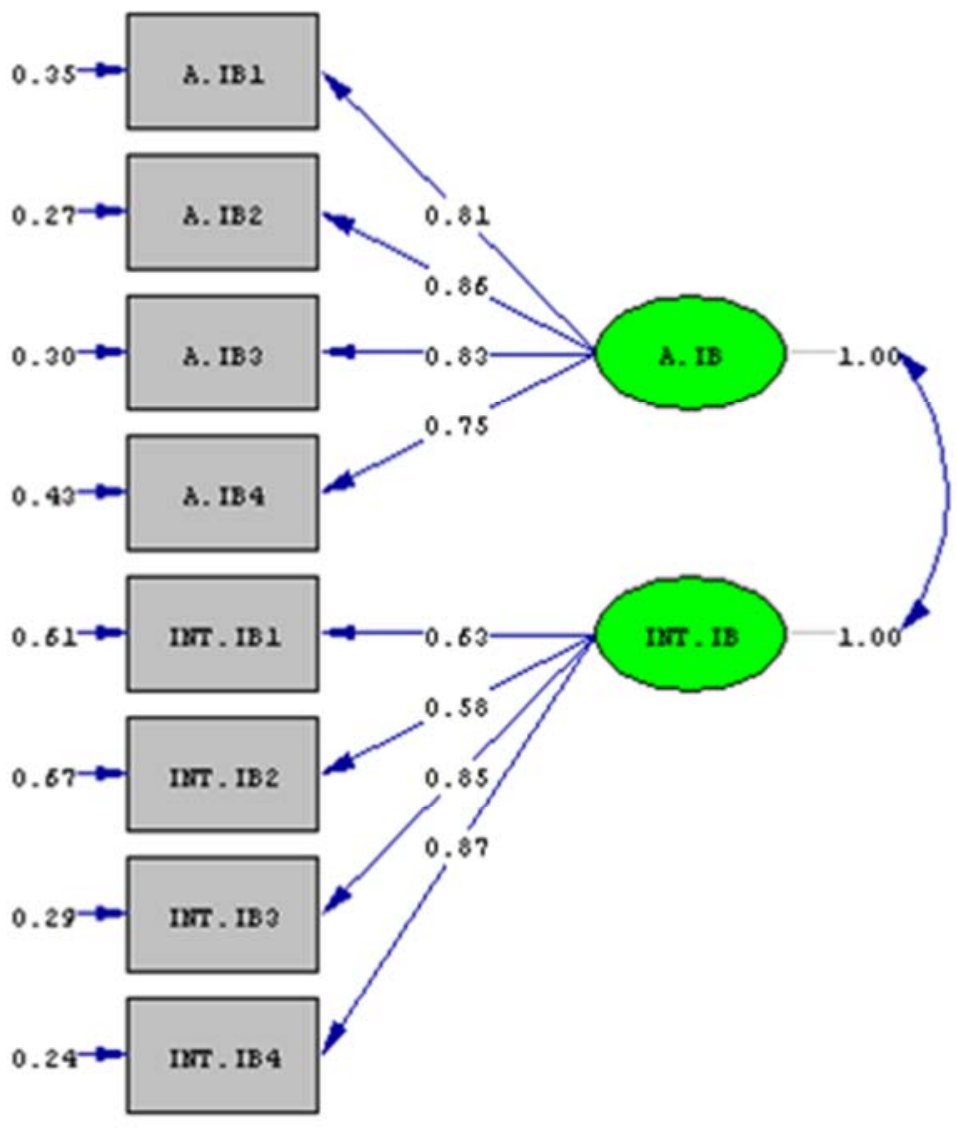

\section{Chi-Square $=61.41, d f=19, \mathrm{P}-\mathrm{value}=0.00000, \mathrm{RMSEA}=0.072$}

Figure 5 The model for measuring endogenous variables in standard numbers mode.

In Figure (5), the relationship between questionnaire questions and the intrinsic variables, the tendency to accept and EPT, using the gamification has shown that RMSEA index is less than 0.08 and Chi square has a degree of freedom of 3.23, which shows the appropriateness of the model. 


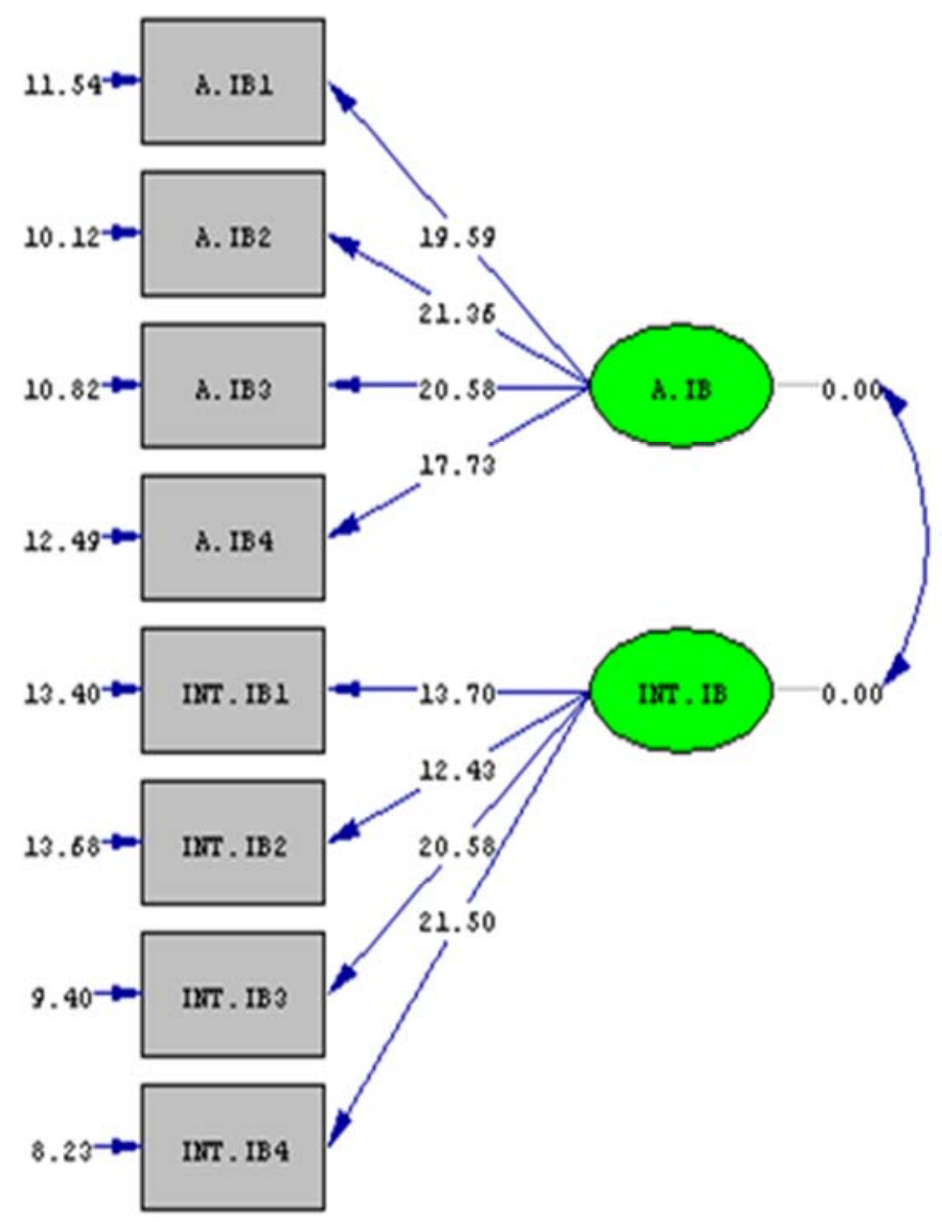

\section{Chi-Square $=61.41, \mathrm{df}=19, \mathrm{P}-\mathrm{value}=0.00000, \mathrm{RMSEA}=0.072$}

Figure 6 The model for measuring endogenous variables in significant numbers mode.

Table 6

\begin{tabular}{|c|c|c|c|c|c|c|c|}
\hline \multicolumn{6}{|c|}{ Fit indices of the research model for measuring model of the endogenous variable } \\
\hline Index & RMSEA & $\frac{x^{2}}{d_{f}}$ & GFI & IFI & CFI & NFI & NNFI \\
\hline Value & 0.072 & 3.23 & 0.91 & 0.93 & 0.93 & 0.92 & 0.89 \\
\hline Desired mode & $0 \leq \& \leq 0.1$ & $1 \leq \& \leq 5$ & $0.8 \leq \& \leq 1$ & $0.8 \leq \& \leq 1$ & $0.8 \leq \& \leq 1$ & $0.8 \leq \& \leq 1$ & $0.8 \leq \& \leq 1$ \\
\hline
\end{tabular}

Figure (6) shows the relevance of each question of the questionnaire to the desired variable. The fit indices in terms of fitness show that the model is approached appropriately, as Chi-square ratio to the degree of freedom is less than 4, RMSEA is below 0.08, and IFI and CFI indices are above 0.90, and only NFI, GFI, and NNFI indices are above $80 \%$ showing that the model is above the average.

According to the model of exogenous variables and index tables, it is seen that all $t$ values in significant numbers states are greater than 1.96 showing that all the correctness of the questions designed for exogenous variables is confirmed. In simpler terms, the model for measuring exogenous variables is confirmed. 


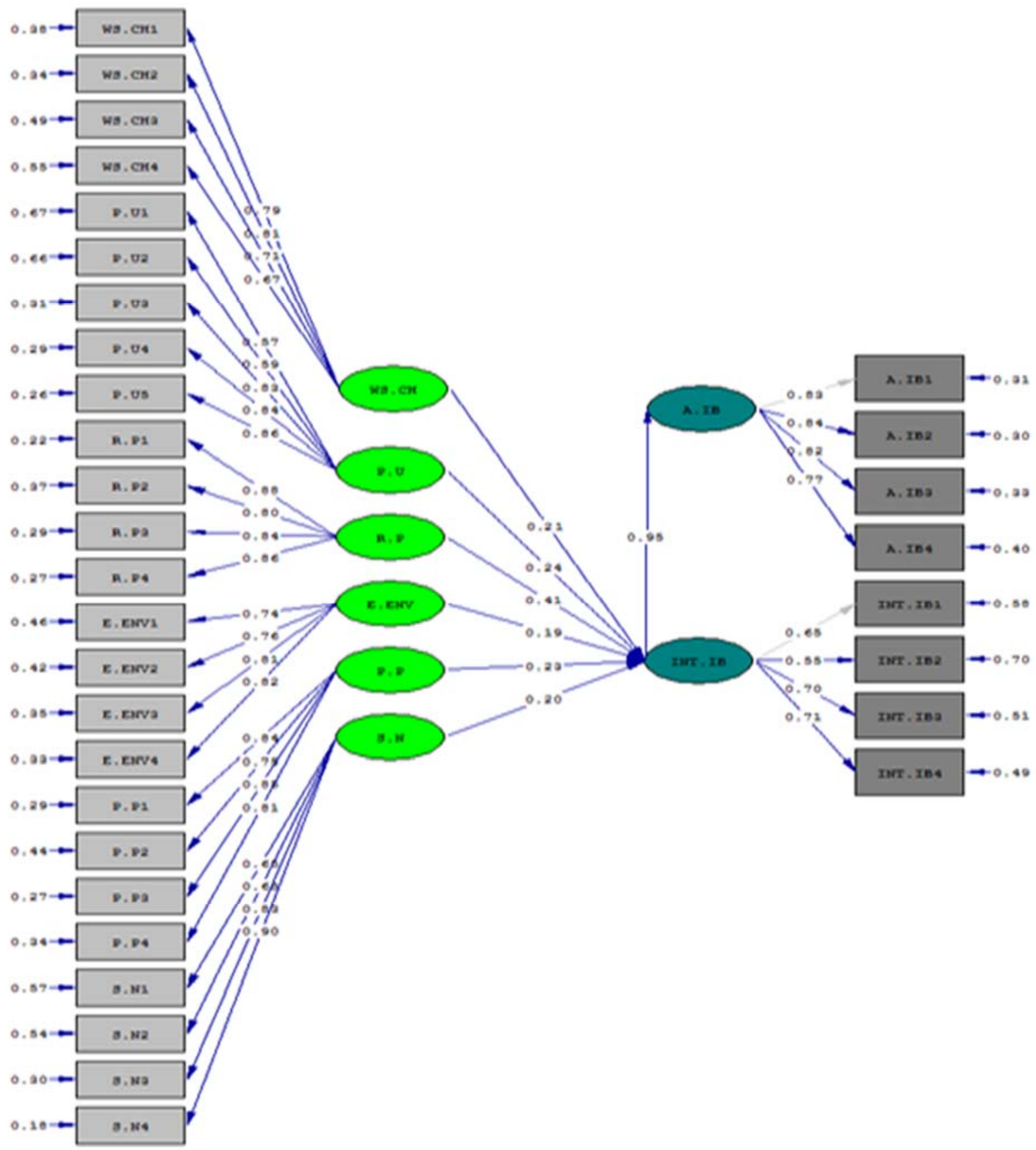

Chi-square=1676.94, $d f=473, p$-value=0.00000, RMsEA=0.078

Figure 7 Testing the research model (Standard Mode). 


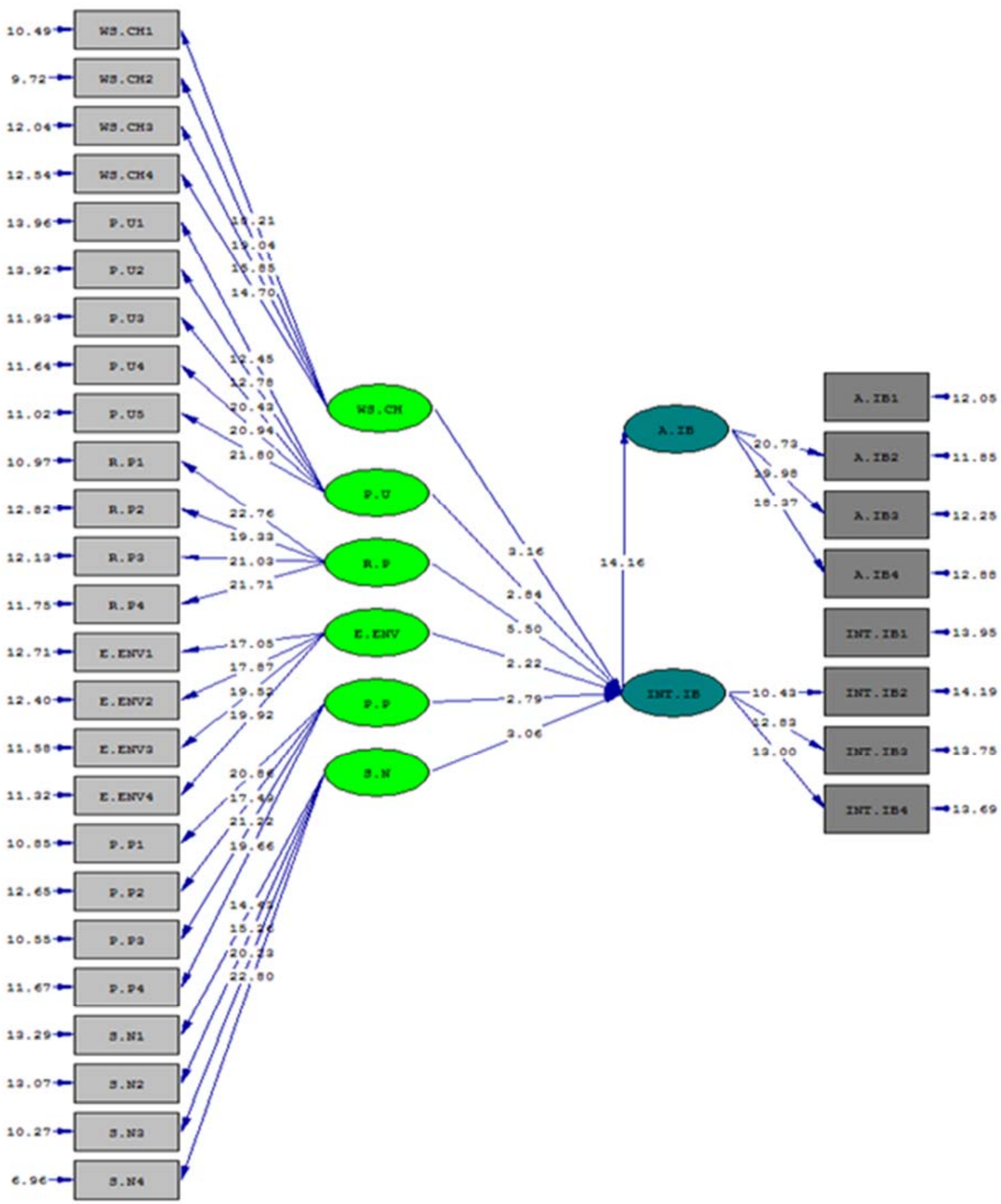

Chi-Square $=1676.94, d f=473, p-v a l u e=0.00000$, RMSEA $=0.078$

Figure 8 Testing the research model (significant numbers mode).

As the software output, the standard estimates as well as significant numbers show, the table of indirect effects of the variables of the model is calculated in Table (7). 
Table 7

\begin{tabular}{|c|l|}
\hline & Path analysis results in the structural model. \\
\hline Indirect effect & \multicolumn{1}{c|}{ Path } \\
\hline$(0.21)(0.95)=0.20(3.16)(14.16)$ & PE $\rightarrow$ Tendency to accept $\rightarrow$ EPT \\
\hline$(0.24)(0.95)=0.23(2.84)(14.16)$ & EE $\rightarrow$ Tendency to accept $\rightarrow$ EPT \\
\hline$(0.41)(0.95)=0.39(5.50)(14.16)$ & SI $\rightarrow$ Tendency to accept $\rightarrow$ EPT \\
\hline$(0.23)(0.95)=0.22(2.79)(14.16)$ & PPs $\rightarrow$ Tendency to accept $\rightarrow$ EPT \\
\hline$(0.19)(0.95)=0.18(2.22)(14.16)$ & FC $\rightarrow$ Tendency to accept $\rightarrow$ EPT \\
\hline$(0.20)(0.95)=0.19(3.06)(14.16)$ & PN $\rightarrow$ Tendency to accept $\rightarrow$ EPT \\
\hline Note: The numbers in the row above are the path coefficients and the lower-row numbers the \\
\hline
\end{tabular}

According to these calculations, it is seen that SI has the most indirect effect on EPT through the tendency to accept.

The following table shows fit and significance indices of the model.

Table 8

\begin{tabular}{|c|c|c|c|c|}
\hline & \multicolumn{4}{|c|}{ Significance and model fit indices } \\
\hline Results & $\begin{array}{c}\text { Value obtained } \\
\text { from the model }\end{array}$ & Is more fit & Abbreviation & Index \\
\hline Confirmed & 0.078 & Smaller than 0.1 & RMSEA & $\begin{array}{c}\text { Root Mean Square Error } \\
\text { of Approximation }\end{array}$ \\
\hline Confirmed & 0.81 & $\begin{array}{c}\text { Equal to or smaller } \\
\text { than 5 }\end{array}$ & $\begin{array}{c}x^{2} \\
d_{f}\end{array}$ & $\begin{array}{c}\text { Chi square to degree of } \\
\text { freedom }\end{array}$ \\
\hline Confirmed & 0.88 & Greater than 0.8 & NNFI & Goodness-of-fit indices \\
\hline Confirmed & 0.86 & Greater than 0.8 & NFI & Normed fit index \\
\hline Confirmed & 0.90 & Greater than 0.8 & CFI & Comparative fit index \\
\hline Confirmed & 0.90 & Greater than 0.8 & IFI & Incremental fit index \\
\hline
\end{tabular}

In this section, the results obtained from the use of inferential methods are presented as SEM:

\section{PE affects EPT with gamification.}

According to the research model in significant numbers mode, the t-value between the two variables equals 3.16, and as this is outside the range -1.96 and 1.96, the hypothesis is confirmed. According to the standard coefficient, one can state that the effect of PE on EPT with gamification is 0.21 .

\section{EE affects EPT with gamification.}

According to the research model in significant numbers mode, the t-value between the two variables equals 2.84 , and as this is outside the range -1.96 and 1.96 , the hypothesis is confirmed. According to the standard coefficient, one can state that the effect of EE on EPT with gamification is 0.24.

\section{SI affects EPT with gamification.}

According to the research model in significant numbers mode, the t-value between the two variables equals 5.50, and as this is outside the range -1.96 and 1.96, the hypothesis is confirmed. According to the standard coefficient, one can state that the effect of SI on EPT with gamification is 0.41. 


\section{PPs affect EPT with gamification.}

According to the research model in significant numbers mode, the t-value between the two variables equals 2.79 , and as this is outside the range -1.96 and 1.96 , the hypothesis is confirmed. According to the standard coefficient, one can state that the effect of PPs on EPT with gamification is 0.23 .

\section{FC affects EPT with gamification.}

According to the research model in significant numbers mode, the t-value between the two variables equals 2.22, and as this is outside the range -1.96 and 1.96, the hypothesis is confirmed. According to the standard coefficient, one can state that the effect of FC on EPT with gamification is 0.19 .

\section{Subjective norms affect EPT with gamification.}

According to the research model in significant numbers mode, the t-value between the two variables equals 3.06, and as this is outside the range -1.96 and 1.96, the hypothesis is confirmed. According to the standard coefficient, one can state that the effect of subjective norms on EPT with gamification is 0.20 .

\section{The tendency to accept e-banking services affects EPT with gamification.}

According to the research model in significant numbers mode, the t-value between the two variables equals 14.16, and as this is outside the range -1.96 and 1.96, the hypothesis is confirmed. According to the standard coefficient, one can state that the effect of tendency to accept e-banking services on EPT with gamification is 0.95 .

\section{Conclusion}

The purpose of the study was to examine EPT using gamification by Saman Bank customers in West Azerbaijan. The population of the study was the customers of Saman Bank, West Azerbaijan using banking services.

The mean PE is 3.8883, with a standard deviation of 0.67393 and a variance of 0.445 . Moreover, the lowest score was for PE equal to 1 and the highest score was 5, and the mean obtained was more than the expected average (score 3 ).

The mean EE is 4.0395, with a standard deviation of 0.56222 and a variance of 0.316 . Moreover, the lowest score was for PE equal to 1.8 and the highest score was 5, and the mean obtained was more than the expected average (score 3).

The mean SI is 3.3881, with a standard deviation of 0.67741 and a variance of 0.459 . Moreover, the lowest score was for SI equal to 1.5 and the highest score was 5 , and the mean obtained was more than the expected average (score 3).

The mean EPT is 3.5174, with a standard deviation of 0.64264 and a variance of 0.413 . Moreover, the lowest score was for EPT equal to 1 and the highest score was 5, and the mean obtained was more than the expected average (score 3 ).

The mean FC is 3.3573, with a standard deviation of 0.61323 and a variance of 0.376 . Moreover, the lowest score was for EPT equal to 1.75 and the highest score was 5, and the mean obtained was more than the expected average (score 3 ).

The PPs mean is 3.9277, with a standard deviation of 0.48932 and a variance of 0.239 . Moreover, the lowest score was for EPT equal to 2.5 and the highest score was 5, and the mean obtained was more than the expected average (score 3 ).

The mean subjective norm is 3.7865 , with a standard deviation of 0.5429 and a variance of 0.295 . Moreover, the lowest score was for EPT equal to 2 and the highest score was 5, and the mean obtained was more than the expected average (score 3 ).

The mean EPT score is 3.8171, with a standard deviation of 0.60417 and a variance of 0.365 . Moreover, the lowest score was for EPT equal to 1.75 and the highest score was 5, and the mean obtained was more than the expected average (score 3 ).

After testing the hypotheses, all the hypotheses were confirmed as follows:

- Considering the first hypothesis where PE was dealt with, by looking at the model in a significance mode, one should state that the hypothesis was confirmed and by referring to the main model in the standard mode it was observed that the effect was +0.21 .

- Considering the second hypothesis where EE was dealt with, by looking at the model in a significance mode, one should state that the hypothesis was confirmed and by referring to the main model in the standard mode, it was observed that the effect was +0.24 .

- Considering the first hypothesis where SI was dealt with, by looking at the model in a significance mode, one should state that the hypothesis was confirmed and by referring to the main model in the standard mode it was observed that the effect was +0.41 .

- Considering the first hypothesis where PPs was dealt with, by looking at the model in a significance mode, one should state that the hypothesis was confirmed and by referring to the main model in the standard mode, it was observed that the effect was +0.23 . 
- Considering the first hypothesis where FC was dealt with, by looking at the model in a significance mode, one should state that the hypothesis was confirmed and by referring to the main model in the standard mode it was observed that the effect was +0.19 .

- Considering the first hypothesis where subjective norm was dealt with, by looking at the model in a significance mode, one should state that the hypothesis was confirmed and by referring to the main model in the standard mode, it was observed that the effect was +0.20 .

- Considering the first hypothesis where EPT was dealt with, by looking at the model in a significance mode, one should state that the hypothesis was confirmed and by referring to the main model in the standard mode, it was observed that the effect was +0.95 .

\section{References}

[1] Asrebank., 2015, The seven dominant digital banking / gamification / embedding banking roles. Recovery from the bank's age: To: http://asrebank.ir/news

[2] Bakhshali, F., 2010, Investigating the Effects of Effective Factors on the Acceptance and Use of E-banking. Journal of Organizational Culture Management, 147

[3] Çelik, H. (2008), "What determines Turkish customers' acceptance of internet banking?", International Journal of Bank Marketing, Vol. 26 No. 5, pp. 353-370. https://doi.org/10.1108/02652320810894406

[4] Deterding, Sebastian \& Dixon, Dan \& Khaled, Rilla \& Nacke, Lennart. (2011). From Game Design Elements to Gamefulness: Defining Gamification. Proceedings of the 15th International Academic MindTrek Conference: Envisioning Future Media Environments, MindTrek 2011. 11. 9-15. 10.1145/2181037.2181040..

[5] Dezhpasand, F., 2009, Proceedings of the e-commerce conference.

[6] Doayi, H.A., and Kamali, T., 2008, Investigating the Acceptance of E-banking, Journal of Banking and Economics, No. 93, pp. 26-29.

[7] Dool, P., 2016. Measuring the effect of gamification on user adoption of a software application (Master's thesis).

[8] Gee, J.P. (2005) "What Would a State of the Art Instructional Video Game Look Like?," Innovate: Journal of Online Education: Vol. 1 : Iss. 6 , Article 1.

[9] Goudarzi, A., and Zobeidi, H., 2008. The Impact of E-banking Expansion on the Profitability of Iranian Commercial Banks. Quarterly Journal of Economic Research, 10(35), pp.111-140.

[10] Hassani, F., Soltani, S., and Zarabieh, F., 2008, E-banking Management, Sabzan Publications. 3.

[11] Hatami, K., 2018, Gamification in Banking; Domains and Functions. Recovering from May 12, 2019, from MrGamification to: http://www.mrgamification.com

[12] Liao, S., Shao, Y.P., Wang, H. and Chen, A., 1999. The adoption of virtual banking: an empirical study. International journal of information management, 19(1), pp.63-74.

[13] Mahmoudi Meymand, M., Zendehdel, L., and Ahmadnejad, M., 2009, The pattern of internet banking adoption by customers, Excavations Journal of Business Management, No. 2, pp.1-26.

[14] McCallum, S., 2012. Gamification and serious games for personalized health. Study Health Technology Information, 177 , pp.85-96. Retrieved from https://www.ncbi.nih.gov/pubmed/22942036

[15] Moghly, A.R., 2007, Adoption of e-banking among customers of banks in Shiraz, Iran Management Sciences Journal, No. 7.

[16] Osipov, I.V., Nikulchev, E., Volinsky, A.A. and Prasikova, A.Y., 2015. Study of gamification effectiveness in online e-learning systems. International Journal of advanced computer science and applications, 6(2), pp.71-77.

[17] Rahmati, Ghofrani., 2009, Designing a model for explaining the speed of Internet banking acceptance. First International Banking Services Marketing Conference, 22.

[18] Sheikhani, S., 1999, Electronic money from a banking perspective. Economics News Magazine, 83

[19] Venkatesh, V. and Bala, H., 2008. Technology acceptance model 3 and a research agenda on interventions. Decision sciences, 39(2), pp.273-315.

[20] Venkatesh, V. and Davis, F.D., 2000. A theoretical extension of the technology acceptance model: Four longitudinal field studies. Management science, 46(2), pp.186-204.

[21] Venkatesh, V., Thong, J.Y. and Xu, X., 2012. Consumer acceptance and use of information technology: extending the unified theory of acceptance and use of technology. MIS quarterly, 36(1), pp.157-178.

[22] Wang, Yi-Shun \& Wang, Yu-Min \& Lin, Hsin-Hui \& Tang, Tzung-I. (2003). Determinants of User Acceptance of Internet Banking: An Empirical Study. International Journal of Service Industry Management. 14. 501-519. 10.1108/09564230310500192.

[23] Gabriel Jipa, Irinel Marin. (2014). Enterprise gamification in business to consumer (B2C) engagement model. Management Challenges for Sustainable Development.-Bucharest, Romania, 489-496

[24] Huotari, K., \& Hamari, J. (2012). A definition for gamification: anchoring gamification in the service marketing literature. Electronic Markets, 27(1), 21-31. Retrieved from https://ink.springer.com/article/10.1007/s12525-015-0212-z

[25] Bruke, B. (2014, April 4). Gartner Redefines Gamification. Retrieved from https://blogs.gartner.com/brian_burke/2014/04/04/gartnerredefines-gamification/

[26] Goncalo, B., \& Tiago, O. (2017). Why so serious? Gamification impact in the acceptance of mobile banking services. Emerald Insight, 27(1), 118-139. doi:10.1108 